\title{
Hydroclimate of the Last Glacial Maximum and deglaciation in southern Australia's arid margin interpreted from speleothem records (23-15 ka)
}

Pauline C. Treble et al.

Correspondence to: Pauline C. Treble (pauline.treble@ansto.gov.au)

The copyright of individual parts of the supplement might differ from the CC BY 3.0 License. 

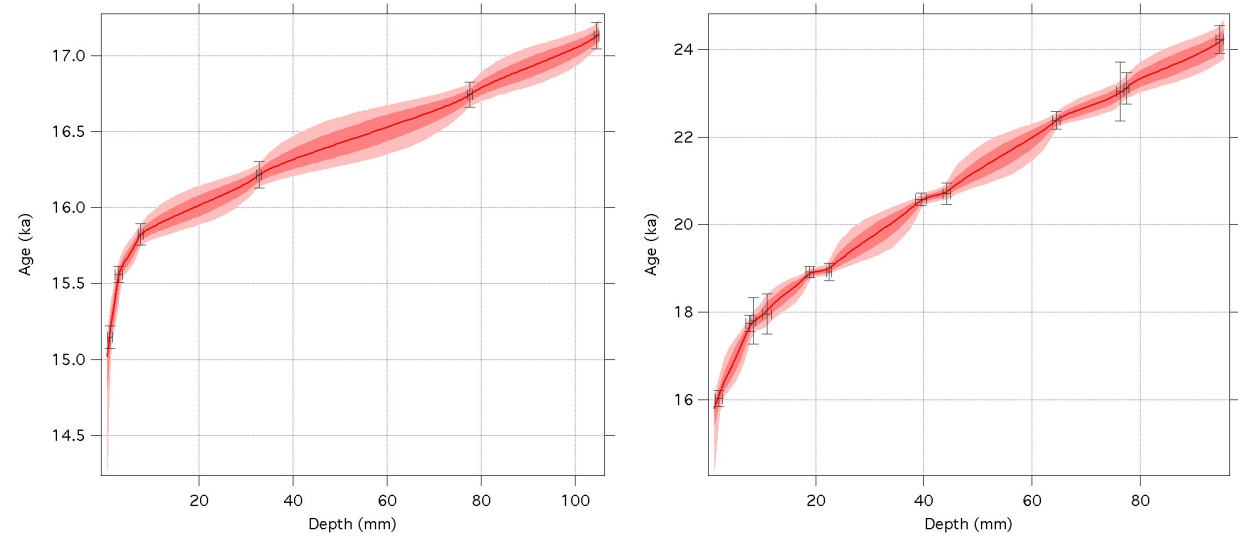

Figure S1: Age versus depth for stalagmites MC-S1 (right) and MC-S2 (left). Error bars are 2 sigma.

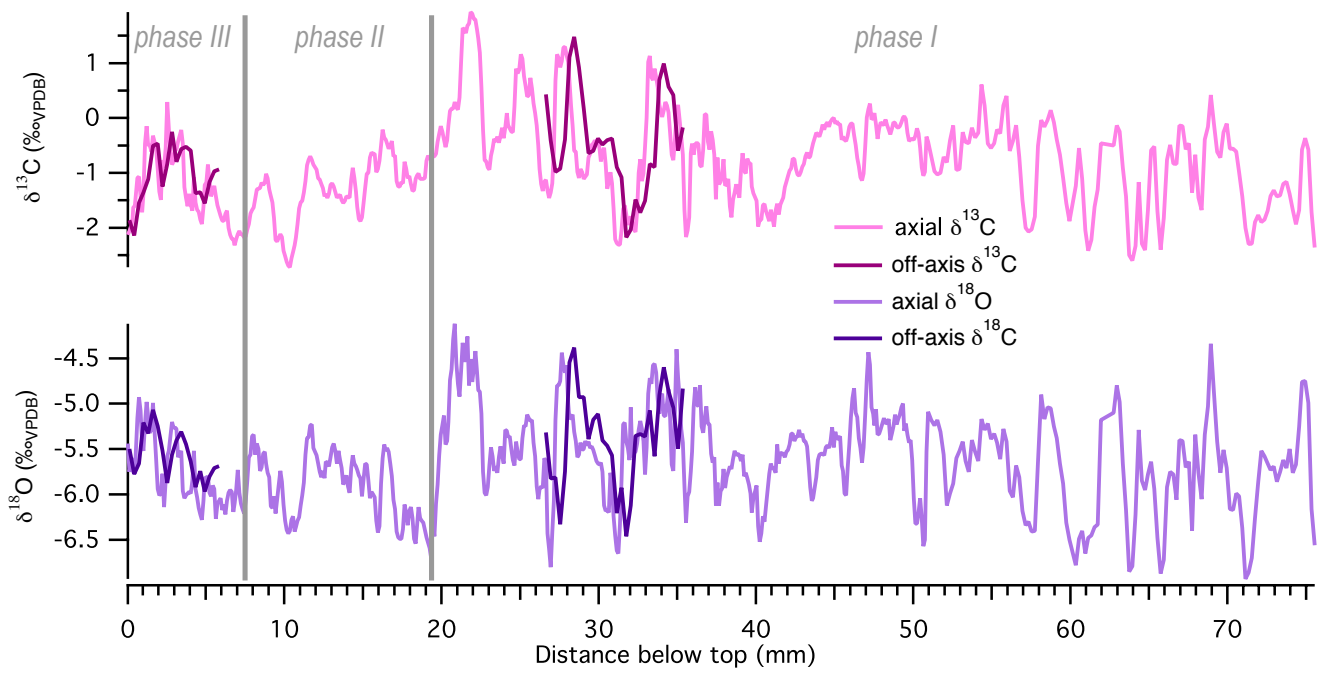

Figure S2: Comparison of $\delta^{18} \mathrm{O}$ and $\delta^{13} \mathrm{C}$ values along the central axis of MC-S2 (paler lines) and with shorter, off-axis transects (13 $\mathrm{mm}$ away). The high overall $\delta^{13} \mathrm{C}$ values for MC-S2 $(-2.5$ to $+1.5 \%)$ indicate that its dripwaters have experienced isotopic enrichment (Dulinski and Rozanski, 1990). However i. low to moderate co-variation between $\delta^{18} \mathrm{O}$ and $\delta^{13} \mathrm{C}(\mathrm{r}=0.7,0.3$ and 0.6 for phases I, II and III, respectively), and ii. good agreement between axial and off-axis transects (13 mm away) suggest that isotopic enrichment is not occurring across the drip impact zone of the stalagmite. The smoother variations and slight shift $(\sim 0.5 \mathrm{~mm})$ of the off-axis transects relative to the central axis is due to the growth laminae thinning slightly towards the edges of the stalagmite.

Co-variation between $\delta^{18} \mathrm{O}$ and $\delta^{13} \mathrm{C}$ for $\mathrm{MC}-\mathrm{S} 1$ is low, indicating that precipitation likely took place in quasi-isotopic equilibrium $r=0.2$ (Fig. 4a-c). 

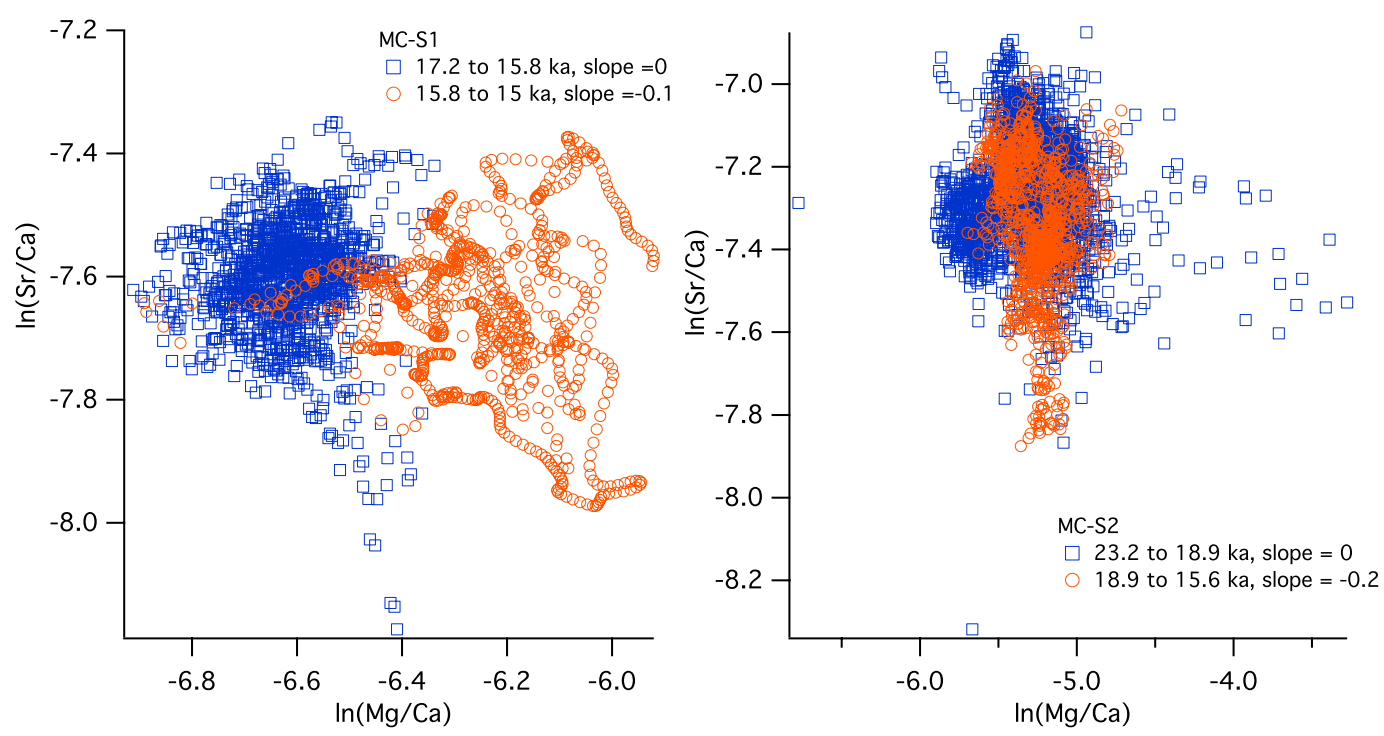

Figure S3: Cross-plots of $\ln (\mathrm{Sr} / \mathrm{Ca})$ versus $\ln (\mathrm{Mg} / \mathrm{Ca})$ (weight ratios) for speleothems MC-S1 (left panel) and MC-S2 (right panel). Slopes range from 0 to 0.2 for each speleothem. A slope of $+0.88 \pm 0.13$ is typically used to diagnose PCP (Sinclair et al., 2012). There appears to be no single common driver for Mg and Sr concentrations in these speleothems. Pearson's Product correlation values (calculated on non ln-transformed data) were: MC-S1 17.2 to $15.8 \mathrm{ka} \mathrm{r}=0,15.8$ to $15 \mathrm{ka} \mathrm{r}=0$; MC-S2 23.2-18.9 $\mathrm{ka} \mathrm{r}=-0.2,18.9$ to $15.6 \mathrm{ka} \mathrm{r}=-0.1$ suggesting that PCP is not dominating these data. 


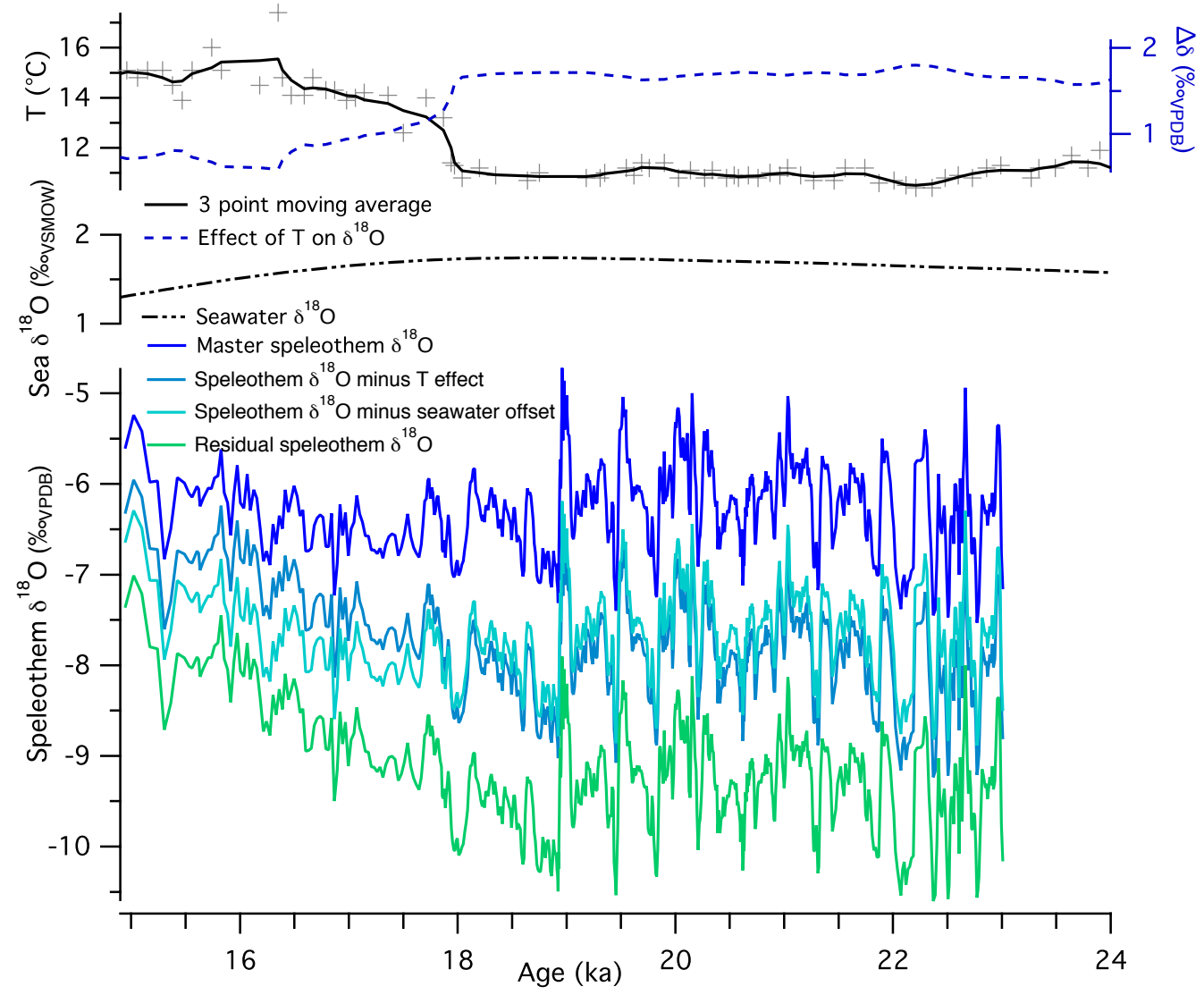

Figure S4: Sea surface temperature (bold unbroken line) from core MD03-2611 (DeDeckker et al., 2012) was twice smoothed with 3 point box smooth converted to the equivalent change in speleothem $\delta^{18} 0$ expected from mean annual cave air temperature variations using $-0.24 \% 0 /{ }^{\circ} \mathrm{C}(\mathrm{a})$; modelled seawater $\delta^{18} \mathrm{O}$ (Bintanja et al., 2008) impacted by enhanced storage of ${ }^{18} \mathrm{O}$ in ice (b); estimated variation in speleothem $\delta^{18} 0$ owing to variation in cave temperature and seawater $\delta^{18} 0$ (c). Deconvolving both the cave temperature and seawater $\delta^{18} 0$ effects suggests that the residual $\delta^{18} 0$ values, approximating dripwater $\delta^{18} 0$, were $\sim 3 \%$ o lower at the LGM (green curve) and that dripwater $\delta^{18} 0$ may have trended upwards by several per mil during the deglaciation. However, are a number of uncertainties need to be taken into account such as the 'precipitation effect' i.e. cooler LGM atmosphere promoting more ${ }^{18} \mathrm{O}$ depleted vapour and hence rainfall $\delta^{18} \mathrm{O}$, would counteract the $\sim 3 \%$ modelled offset. An additional uncertainty is that the estimated impact of the temperature effect depends on the accuracy of the marine temperature reconstruction and its relationship to land temperatures.

\section{References}

Cheng, H., Edwards, R. L., Shen, C. C., Polyak, V. J., Asmerom, Y., Woodhead, J., Hellstrom, J., Wang, Y. J., Kong, X. G., Spotl, C., Wang, X. F., and Alexander, E. C.: Improvements in Th-230 dating, Th-230 and U-234 half-life values, and U-Th 
isotopic measurements by multi-collector inductively coupled plasma mass spectrometry, Earth and Planetary Science Letters, 371, 82-91, 2013.

De Deckker, P., Moros, M., Perner, K., Jansen, E.,: Influence of the tropics and southern westerlies on glacial interhemispheric asymmetry. Nature Geoscience 5, 266-269, 2012.

Dulinski, M. and Rozanski, K.: Formation of ${ }^{13} \mathrm{C} /{ }^{12} \mathrm{C}$ isotope ratios in speleothems: A semi-dynamic model, Radiocarbon, 32, 7-16, 1990. 